Boise State University

ScholarWorks

Geosciences Faculty Publications and

Presentations

Department of Geosciences

$11-2016$

\title{
The Hydrogeologic Information in Cross-Borehole Complex Conductivity Data from an Unconsolidated Conglomeratic Sedimentary Aquifer
}

\author{
Andrew Binley \\ Lancaster University \\ John Keery \\ Lancaster University \\ Lee Slater \\ Rutgers University-Newark \\ Warren Barrash \\ Boise State University \\ Mike Cardiff \\ University of Wisconsin-Madison
}

This document was originally published in Geophysics by Society of Exploration Geophysicists. Copyright restrictions may apply. doi: 10.1190/GEO2015-0608.1 


\title{
The hydrogeologic information in cross-borehole complex conductivity data from an unconsolidated conglomeratic sedimentary aquifer
}

\author{
Andrew Binley ${ }^{1}$, John Keery ${ }^{1}$, Lee Slater ${ }^{2}$, Warren Barrash ${ }^{3}$, and Mike Cardiff ${ }^{4}$
}

\begin{abstract}
Accurate estimation of the hydrological properties of nearsurface aquifers is important because these properties strongly influence groundwater flow and solute transport. Laboratorybased investigations have indicated that induced polarization (IP) properties of porous media may be linked, through either semiempirical or fully mechanistic models, to hydrological properties including hydraulic conductivity. Therefore, there is a need for field assessments of the value of IP measurements in providing insights into the hydrological properties of aquifers. A cross-borehole IP survey was carried out at the Boise Hydrogeophysical Research Site (BHRS), an unconsolidated fluvial aquifer that has previously been well-studied with a variety of geophysical and hydrogeologic techniques. High-quality IP measurements were inverted, with careful consideration of the data error structure,
\end{abstract}

to provide a 3D distribution of complex electrical conductivity values. The inverted distribution was further simplified using $k$-means cluster analysis to divide the inverted volume into discrete zones with horizontal layering. Identified layers based on complex electrical conductivity inversions are in broad agreement with stratigraphic units identified in previous studies at the site. Although mostly subtle variations in the phase angle are recovered through inversion of field data, greater contrasts in the IP data are evident at some unit boundaries. However, in coarse-grained aquifers, such as the BHRS, the discrimination of mildly contrasting lithologic units and associated changes in hydraulic conductivity of one or two orders of magnitude are unlikely to be achieved through field IP surveys. Despite the difficulty of differentiating subtle differences between all units, overall estimates of hydraulic conductivity purely from our field IP data are typically within an order of magnitude of independently measured values.

\section{INTRODUCTION}

Three-dimensional high-resolution information on shallow subsurface structure is needed to improve understanding of groundwater flow, vadose zone moisture dynamics, and solute transport. Such structural information can improve conceptual models required to develop realistic flow and transport simulations. Geophysical imaging has been extensively used for this purpose, driven by technological developments that permit faster and less expensive acquisition of $3 \mathrm{D}$ data sets (Griffiths and Turnbull, 1985; Stummer et al., 2002; Loke et al., 2013). Beyond structural information, it may be possible to estimate hydraulic properties (e.g., porosity $\varnothing$ or ultimately hydraulic conductivity $K$ ) if reliable petrophysical relations can be applied to geophysical images. In particular, the determination of $K$ distribu- tions from geophysical images has been extensively pursued, although experience suggests that achieving this goal requires information from more than a single type of geophysical measurement (Doetsch et al., 2012; Jardani et al., 2013).

Electrical methods hold significant promise because of established physical links to hydrogeologic parameters (e.g., $\varnothing$, pore size distribution, grain size distribution, and surface area) which influence $K$ (Slater and Lesmes, 2002b; Revil and Florsch, 2010). Furthermore, electrical measurements can be acquired over a wide range of scales and with different methods, electrode types, and configurations. The DC resistivity imaging method has been widely applied (Bentley and Gharibi, 2004; Cassiani et al., 2006; Jardani et al., 2013) but is limited in that quantitative hydrogeologic information is challenging to extract from a single type of geophysical

\footnotetext{
Manuscript received by the Editor 7 November 2015; revised manuscript received 16 July 2016; published online 07 September 2016

${ }^{1}$ Lancaster University, Lancaster, UK. E-mail: a.binley@lancaster.ac.uk; john.keery@open.ac.uk.

${ }^{2}$ Rutgers University-Newark, Newark, New Jersey, USA. E-mail: 1slater@ rutgers.edu.

${ }^{3}$ Boise State University, Boise, Idaho, USA. E-mail: wbarrash@cgiss.boisestate.edu.

${ }^{4}$ University of Wisconsin-Madison, Madison, Wisconsin, USA. E-mail: cardiff@wisc.edu.

(C) 2016 Society of Exploration Geophysicists. All rights reserved.
} 
measurement, even with generally available basic supporting information, such as rock or sediment type (e.g., sand or sand with silt or clay). The complex conductivity (or induced polarization [IP]) method holds promise for improving quantification of hydrogeologic properties as information on the interconnected pore volume (e.g., $\varnothing$, tortuosity) and the mineral-fluid interfacial area (e.g., surface area to pore volume $S_{\text {por }}$ and effective grain size) can, in principle, be derived from the complex electrical measurements (Börner et al., 1996; Slater and Lesmes, 2002a; Weller et al., 2013). Recent advances have been made (Slater and Lesmes, 2002b; Revil and Florsch, 2010; Weller et al., 2015) in understanding the link between complex conductivity and hydraulic conductivity, mainly through empirical or semiempirical models (for example, assuming Kozeny-Carman and Archie petrophysics; Archie, 1942; Charbeneau, 1999). However, although inversion tools are now well-established for field application, few studies have attempted to assess the potential of complex conductivity imaging for deriving hydrogeologic information (see, e.g., Hördt et al., 2009; Attwa and Günther, 2013). Furthermore, previous field studies have considered a wide range of hydrologic parameter variation, i.e., several orders of magnitude change in $K$ (Slater and Glaser, 2003; Kemna et al., 2004; Hördt et al., 2007), but in some field settings, more subtle contrasts in hydrogeophysical properties significantly influence the overall system behavior (Sudicky, 1986).

Few, if any, field-scale complex conductivity studies have had strong independent data sets on electrical and hydrologic parameters of the system required for evaluating the information obtainable from the complex conductivity inversion. Here, we report on complex conductivity imaging from a local-scale study $(15-20 \mathrm{~m}$ in all three directions) performed to advance our understanding of the hydrogeologic information (qualitative, semiquantitative, and quantitative) that can be obtained from IP. We take advantage of an exceptionally well-studied natural unconsolidated sedimentary aquifer in which results from previous borehole and borehole-to-borehole geophysical surveys allow us to assess the performance of the complex conductivity imaging. When such borehole arrays are available in unconsolidated aquifers, the spatial characterization of hydraulic conductivity can be estimated by slug tests (Brauchler et al., 2010; Diem et al., 2010; Cardiff et al., 2011; Barrash and Cardiff, 2013), pumping tests (Barrash et al., 2006; Cardiff et al., 2009), and 3D hydraulic tomography (Cardiff et al., 2012, 2013).

The aim of this work is to evaluate the variation in complex electrical conductivity derived from inversion of field data in which high-resolution characterization of hydrogeologic properties already exists. Specifically, we aim to (1) assess the contrast in complex conductivity that results from the variability in physical properties, (2) determine the link (if any) between complex conductivity variability and known hydrostratigraphy, (3) assess the relative value of DC conductivity versus complex conductivity for independent delineation of lithologic units, and (4) offer evidence-based insight into the potential value of field-scale complex conductivity for direct quantitative estimation of key hydrogeophysical properties in similar settings. Slater et al. (2014) describe high-accuracy laboratory spectral IP (SIP) measurements on samples extracted from the study site of this work showing differences in the complex conductivity magnitude associated with grain size variations. However, subtle variations in the polarization relaxation time distributions between units could not be correlated with unit physical properties. Therefore, we restrict our analysis to inversion of the complex conductivity only and do not consider more elaborate inversion methods recently developed to analyze the spectral characteristics of the polarization response timedomain data (Fiandaca et al., 2013).

\section{ELECTRICAL PROPERTIES}

Complex electrical conductivity $\sigma^{*}$ quantifies the ability of a porous medium to transport and store charge. It is usually determined from measurements of the conductivity magnitude $|\sigma|$ and phase shift $\varphi$ of a porous material relative to a reference resistor. The real $\sigma^{\prime}$ and imaginary $\sigma^{\prime \prime}$ components of $\sigma^{*}$ represent electromigration (transport of charge under the influence of an electric field) and polarization (reversible storage of charge under the influence of an electric field) mechanisms, respectively. The measured phase shift $\varphi$ is related to the real and imaginary parts of $\sigma^{*}$ according to

$$
\varphi=\tan ^{-1}\left(\sigma^{\prime \prime} / \sigma^{\prime}\right)
$$

Most models for the complex electrical conductivity of a porous material at low frequencies (e.g., less than $100 \mathrm{~Hz}$ ) are based on charge transfer via a parallel addition of two mechanisms representing (1) an electrolytic contribution via conduction only, without any polarization, through the interconnected pore space $\sigma_{\mathrm{el}}$ and (2) a mineral surface contribution via conduction and polarization within the electrical double layer (EDL) formed at the interfaces of the interconnected pore surface $\sigma_{\text {surf }}^{*}$ (Vinegar and Waxman, 1984) such that $\sigma^{*}=\sigma_{\mathrm{el}}+\sigma_{\text {surf }}^{*}$. Because the electrolyte is essentially unpolarizable at low frequencies, electrolytic conduction is a purely real term so the imaginary component of the overall complex conductivity is derived solely from the mineral surface polarization. The complex surface conductivity associated with the EDL originates from the fixed surface charges (the Stern layer) and the diffuse layer of charges that exchange with the electrolyte. Based on this parallel conduction model,

$$
\begin{gathered}
\sigma^{\prime}=\sigma_{\mathrm{el}}+\sigma_{\text {surf }}^{\prime}, \\
\sigma^{\prime \prime}=\sigma_{\text {surf }}^{\prime \prime},
\end{gathered}
$$

and for low-phase angles, where $\sigma^{\prime \prime} \ll \sigma^{\prime}$, and $\tan ^{-1}\left(\sigma^{\prime \prime} / \sigma^{\prime}\right) \cong$ $\sigma^{\prime \prime} / \sigma^{\prime}$,

$$
\varphi \cong \frac{\sigma_{\text {surf }}^{\prime \prime}}{\sigma_{\mathrm{el}}+\sigma_{\text {surf }}^{\prime}}(\varphi<100 \mathrm{mrad})
$$

where $\sigma^{\prime \prime}$ represents a direct measure of the polarization of the interconnected pore surface and $\varphi$ represents the ratio of this polarization to the combined conduction mechanisms within the sample.

The dependence of $\sigma^{\prime \prime}$ on the pore-normalized internal surface area $S_{\text {por }}$ (Börner, 1992; Weller et al., 2013) and grain size (Revil and Skold, 2011; Vaudelet et al., 2011) has encouraged many efforts to use complex conductivity measurements to predict $K$ (Slater and Lesmes, 2002b; Revil and Florsch, 2010). Furthermore, the dependence of $\sigma^{\prime \prime}$ on $\sigma_{w}$ is relatively weak. Weller and Slater (2012) report measurements on 67 sandstone and unconsolidated samples where $\sigma^{\prime \prime} \propto \sigma_{w}^{b}(0.18<b<0.55$, with the dimensionless exponent $b$ having a mean value of 0.34 ). Consequently, $\sigma^{\prime \prime}$ is generally considered as an excellent indicator of lithologic variability due to (1) its pri- 
mary dependence on $S_{\text {por }}$ and grain size and (2) its weak dependence on pore-fluid conductivity and saturation relative to real conductivity (when dominated by $\sigma_{\mathrm{el}}$ ).

\section{HYDROGEOPHYSICAL SETTING}

The Boise Hydrogeophysical Research Site (BHRS) was established in recognition of the need for improved methods for characterization of permeability distributions in heterogeneous aquifers (Barrash et al., 1999; Clement et al., 1999). The site is situated on a gravel bar beside the Boise River approximately $12 \mathrm{~km}$ upstream from downtown Boise, Idaho.

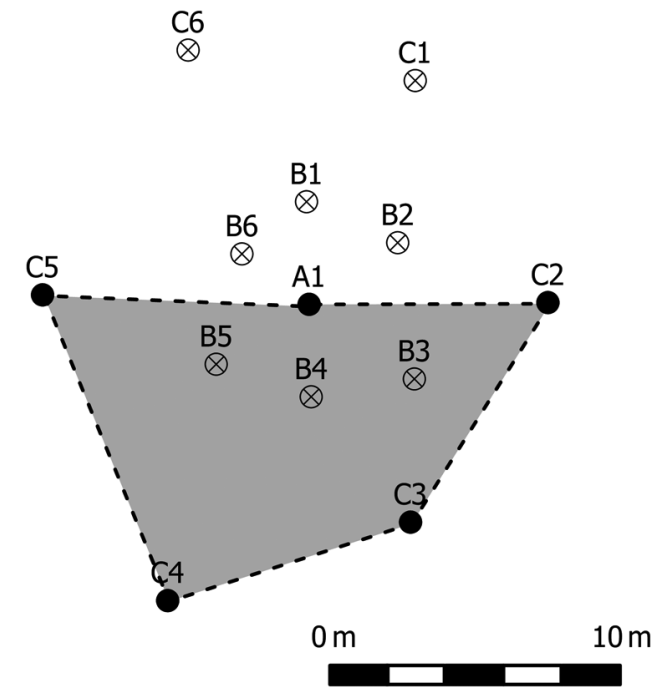

Figure 1. Layout of central well field at the BHRS. Solid symbols show location of electrode arrays. Shaded zone indicates area of investigation in this study.
The unconsolidated sediments of the unconfined aquifer at the BHRS have a thickness of approximately $20 \mathrm{~m}$ and lie above lowpermeability red clay (Barrash and Clemo, 2002). A combined drilling and core recovery technique was applied in 1997 and 1998 to construct 18 wells at the BHRS. All wells are screened throughout the unconfined sand and cobble aquifer. The central area of the well field is composed of 13 boreholes (Barrash et al., 1999) with a central borehole (A1) surrounded by an inner ring of six boreholes, designated B1-B6, approximately 3-4 m from A1 (Figure 1). A second ring of six boreholes, designated $\mathrm{C} 1-\mathrm{C} 6$, is positioned approximately 7-10 $\mathrm{m}$ from $\mathrm{A} 1$, with boreholes in the inner and second rings offset by an angle of approximately $30^{\circ}$. Five additional peripheral boreholes, designated X1-X5, are positioned around the central area.

Barrash and Clemo (2002) investigate the subsurface at the BHRS with a neutron logging survey; example $\varnothing$ profiles derived from this analysis are shown in Figure 2. Barrash and Clemo (2002) apply a hierarchical geostatistical approach to the porosity data, which supported the recognition of five stratigraphic units (numbered 1-5 in depositional sequence order) and recognition of variability and smaller scale facies within some units. In this stratigraphy, units 1-4 are dominated by cobbles and unit 5 is a sand channel, which is thickest close to the river, thins away from the river, and pinches out in the center of the well field. Of the cobble-dominated units, units 1 and 3 are very similar and have relatively low $\varnothing$ and variance, whereas units 2 and 4 have higher $\varnothing$ and variance (Barrash and Clemo, 2002). This porosity stratigraphy is supported by lithologic stratigraphy based on core (Barrash and Reboulet, 2004).

A few geophysical surveys have been previously carried out at the site. Tronicke et al. (2004) gather a set of GPR measurements from the BHRS, with the transmitter and receiver deployed in $\mathrm{C} 5$ and $\mathrm{C} 6$, and note that values of $\varnothing$ derived from an inversion of the GPR data differed in detail from the layered stratigraphy identified by Barrash and Clemo (2002), but a cluster analysis of the inverted

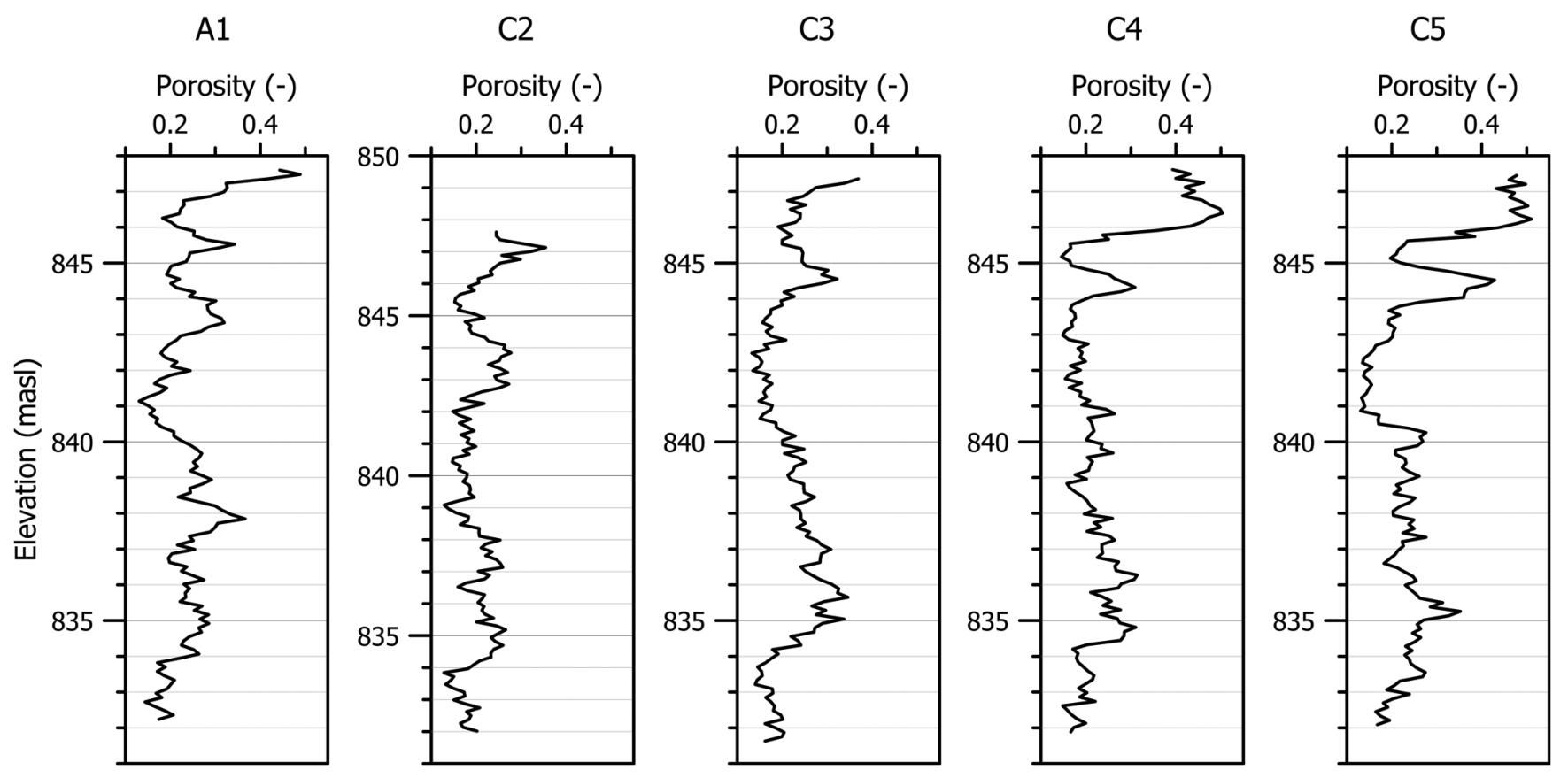

Figure 2. Example porosity profiles from central well field borehole logs. 
GPR data identified clusters with similar values of velocity and attenuation, broadly corresponding to areas with contrasting $\varnothing$ values. Furthermore, crosshole GPR analysis was conducted by Ernst et al. (2007) and Irving et al. (2007). Dafflon et al. (2011b) invert multiple intersecting high-resolution crosshole GPR profiles at the BHRS and obtain a 3D distribution of $\varnothing$ values that are in broad agreement with the results of the geostatistical study by Barrash and Clemo (2002).

The original five-unit stratigraphy was extended following the capacitive probe resistivity (CR) well logging outlined in Mwenifumbo et al. (2009). With this technique, the electrical resistivity close to the well is measured using two pairs of coaxial metal cylinders forming a transmitter capacitor and a receiver capacitor, operating at a frequency of approximately $1 \mathrm{MHz}$. These CR results revealed contrasting electrical properties in one of the cobble units, unit 2, which led to a new classification of units $2 \mathrm{~A}$ and $2 \mathrm{~B}$ (with the upper unit, 2B, having higher electrical resistivity than the lower unit, 2A). Figure 3 shows the stratigraphy in well $\mathrm{C} 4$ for example. Some of the unit boundaries, in particular, those defining unit 4 , are clearly visible in the porosity log, whereas for others, the contrast is more subtle. This is further demonstrated by the CR $\log$ for well $\mathrm{C} 4$, in which the lower boundaries of units $2 \mathrm{~A}$ and $2 \mathrm{~B}$ are also clearly visible.

In a laboratory study of electrical and hydrologic properties of core samples from the BHRS, Slater et al. (2014) investigate links between sediment grain size distributions and $K$ and demonstrate the importance of analyzing only the matrix sediment within the cobble framework (i.e., excluding the cobble fraction). They find that, typical of many unconsolidated sediments, the variation in the relaxation time distribution $(0.001-1000 \mathrm{~Hz})$ between different units was small. No relationship between the relaxation time distribution (frequency response) and pore geometric properties was observed. Instead, the sediments approximated a constant phase angle behavior from 0.001 to $10 \mathrm{~Hz}$. However, Slater et al. (2014) do find a relationship between imaginary conductivity (polarization strength) and grain diameter that was subsequently used to test predictions of hydraulic conductivity at this site. They note that for BHRS sediments, $d_{60[\text { matrix] }}$, the grain size for which $60 \%$ of a sample of the matrix is smaller, appeared to be a representative grain size for the prediction of $K$ from the Kozeny-Carman type models, although they emphasized that no single grain size has been shown to be representative for all aquifer materials. Figure 3 includes the profile of particle size for well $\mathrm{C} 4$, shown as $d_{60[\text { matrix] }}$, obtained from grain size analysis of the sediment cores, after exclusion of cobbles. Subtle changes in $d_{60[\text { matrix }]}$ are discernible at the boundaries between units $2 \mathrm{~A}$ and $2 \mathrm{~B}$, between units $2 \mathrm{~B}$ and 3 , and between units 3 and 4 .

A high-resolution distribution of the six stratigraphic layers in the central region of the BHRS was developed following Barrash and Clemo (2002) and Mwenifumbo et al. (2009) to provide a "ground-truth," not only primarily of porosity distributions but also of electrical parameters, against which results of other geophysical surveys can be compared. The distribution is based on a kriged geostatistical model that includes all stratigraphic unit contact elevations in the wells. The model adopts a stationary random field with exponential covariance function with sill $1 \mathrm{~m}^{2}$ and horizontal correlation length $10 \mathrm{~m}$. The contact between units 4 and 5 showed drift that was

Figure 3. Profiles at borehole C4: (a) unit boundaries, (b) porosity, (c) $d_{60}$ for the matrix only $\left(d_{60[\text { matrix }]}\right)$, and (d) CR. Sources: Barrash and Clemo (2002), Reboulet and Barrash (2003), Mwenifumbo et al. (2009), and Barrash and Cardiff (2013).

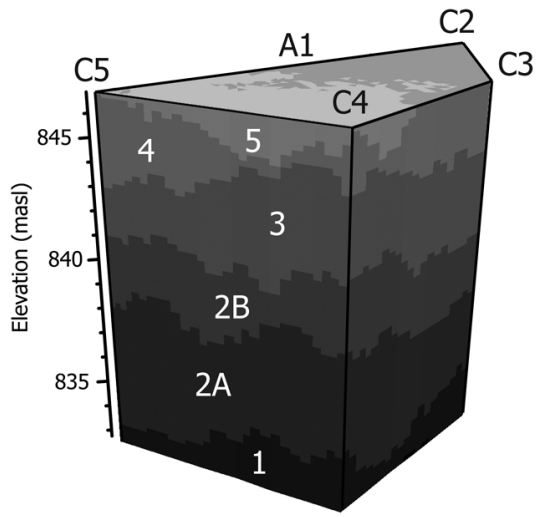

Figure 4. Example unit boundary realization based on a geostatistical model of unit contacts. accounted for in the model. Figure 4 shows an example realization from this approach.

\section{Hydraulic conductivity from multilevel slug tests}

Recent work by Barrash and Cardiff (2013) using high-resolution data from multilevel slug tests has investigated variation of $K$ within the BHRS. Details of the slug-test procedures, data quality assessment, and analysis are given in Malama et al. (2011), Cardiff et al. (2011), and Barrash and Cardiff (2013). Figure 5 shows example $K$ profiles from a few wells within the central well field.

Slug tests were run at two or three different slug heights per zone (Butler, 1998) with highly repeatable results (differences between $K$ from such repeated tests are generally $<20 \%$ with the occasional poor-quality test excluded from averaging for a given zone). Values of $K$ identified from the slug tests were corroborated with independent hydraulic tomography results (Cardiff et al., 2013) and clearly 
show that although $K$ is not positively correlated with $\varnothing$ or geophysical parameters for all stratigraphic units, $K$-facies can be identified with multivariate statistical analysis within the established $\varnothing-$ CR stratigraphy (Barrash and Cardiff, 2013). This, along with $K$-facies boundaries commonly terminating at $\varnothing-\mathrm{CR}$ unit contacts, supports the interpretation that $K$ structure is based on sedimentary origins (as are $\varnothing$ and lithology). One of the $K$-facies has the highest $K$ of all and is generally coincident with unit 2B, which has the highest CR of all. Although $K$-facies within units $1-2 \mathrm{~B}$ tend to have a positive association of $K$ with $\varnothing, K$-facies within units 3-4 tend to have a negative association of $K$ with $\varnothing$ (Barrash and Cardiff, 2013).

Examination of grain-size distribution parameters (including cobble size and percent of the sample, $d_{10}$ and sorting for the whole sample and for the matrix alone) indicates that multiple combinations of these parameters with $\varnothing$ may be associated with similar values of $K$, but there are tendencies for certain combinations to occur within particular types of $K$-facies (Barrash and Cardiff, 2013). CR and $\varnothing$ were negatively correlated at lower values of $K$ but positively correlated at higher values of $K$. Some positive correlation between CR and the degree of sorting was also observed. The distribution of $K$ in these conglomeratic sediments shows a more complex relationship with geophysical properties than in sand-dominated unconsolidated aquifers in which Kozeny-Carman and Archie petrophysics may be more consistently applicable (Barrash and Cardiff, 2013).

Heterogeneity in $K$ is not great at the BHRS (slightly more than two orders of magnitude for most of the aquifer). The variance of $\ln$ $K$ is 0.49 , more than three times the $\ln K$ variance at the well-studied aquifer of Cape Cod (Wolf et al., 1991) and less than twice that of the aquifer at Borden (Woodbury and Sudicky, 1991). However, tracer behavior at the BHRS (Johnson et al., 2007; Nelson, 2007; Dafflon et al., 2011a) is clearly not representative of a homogeneous or simple layered medium in $K$ (or $\varnothing$ ).

\section{METHODS}

Our investigation was designed to collect high-resolution complex electrical data with a low and known error structure, suitable for analysis using existing 3D inversion tools, to provide distributed values of complex electrical parameters for direct comparison with existing stratigraphic models of the BHRS and, where practical, to allow relationships between electrical and hydrologic parameters to be investigated. In the following sections, we describe the geophysical measurements, discuss error analysis, summarize the inversion, and introduce the statistics used to understand the inversion results.

\section{Complex resistivity measurements}

In June 2010, a crosshole complex resistivity survey was conducted at the BHRS. Here, we report on analysis of data from wells A1, C2, C3, C4, and C5 (Figure 1). Two electrode arrays, each with 24 stainless steel mesh electrodes spaced $0.61 \mathrm{~m}$ apart, were used for measurements between pairs of boreholes in this group of five wells. Well A1 was common to all borehole pairs, and thus, the measurement set comprises pairs: $\mathrm{A} 1-\mathrm{C} 2$, A1-C3, A1-C4, and A1-C5. This arrangement eliminated the need to remove and relocate one of the electrode arrays while still maintaining 3D coverage over the well cluster.

As each well is fully screened, electrical contact with the formation is achievable beneath the water table. The top electrode in each well was sited at 846.87 meters above sea level (masl), equivalent to $2.67 \mathrm{~m}$ depth at A1. Recognizing the potential impact of current channeling through the water column in the well (Nimmer et al., 2008), insulating spacers were installed between electrodes to reduce these effects.

Preliminary field and modeling trials were conducted to determine suitable measurement configurations to meet resolution and data quality objectives. Following these trials, a dipole-dipole arrangement was selected using a "skip five" protocol (dipole spacing of six electrodes), with forward and reciprocal measurements to allow the error structure to be estimated (Slater et al., 2000) with a current and potential dipole spacing of $3.66 \mathrm{~m}$. For each borehole pair, 922 direct measurements (and the associated reciprocal configuration) were collected using an Iris Syscal Pro instrument (Iris Instruments, Orleans, France). Each measurement set (i.e., one borehole pair) took approximately $110 \mathrm{~min}$ to collect. Time-domain IP measurements were computed based on a total of 20 windows sampled using a current waveform with $1 \mathrm{~s}$ on time, $1 \mathrm{~s}$ off time, $0.12 \mathrm{~s}$ delay time, and individual window length of $0.04 \mathrm{~s}$ (total window length of $0.8 \mathrm{~s}$ ). The $0.12 \mathrm{~s}$ delay time removes any effect of the instrument's low-pass filter (as reported by Fiandaca et al., 2012; Iris Instruments, personal communication, 2015).

The IP measurements provide a transfer resistance magnitude (or apparent resistivity/conductivity) and an integral chargeabilty $M$. Following Mwakanyamale et al. (2012), who use the same instrument settings, we related the complex conductance phase shift $(\varphi)$ at the current cycle frequency $(0.25 \mathrm{~Hz})$ to $M$ through the relationship $\varphi \approx 1.3 M$, where $\varphi$ is in $\mathrm{mrad}$, and $M$ is in $\mathrm{mV} / \mathrm{V}$. We note that, following the analysis of Kemna et al. (1997), the equivalent scaling factor is 1.5 rather than 1.3 at a corresponding $0.025 \mathrm{~Hz}$ current injection frequency.

\section{Error analysis}

Quantification of errors is essential for data inversion to ensure (1) that individual measurements can be appropriately weighted and (2) that appropriate convergence of the inversion process can be

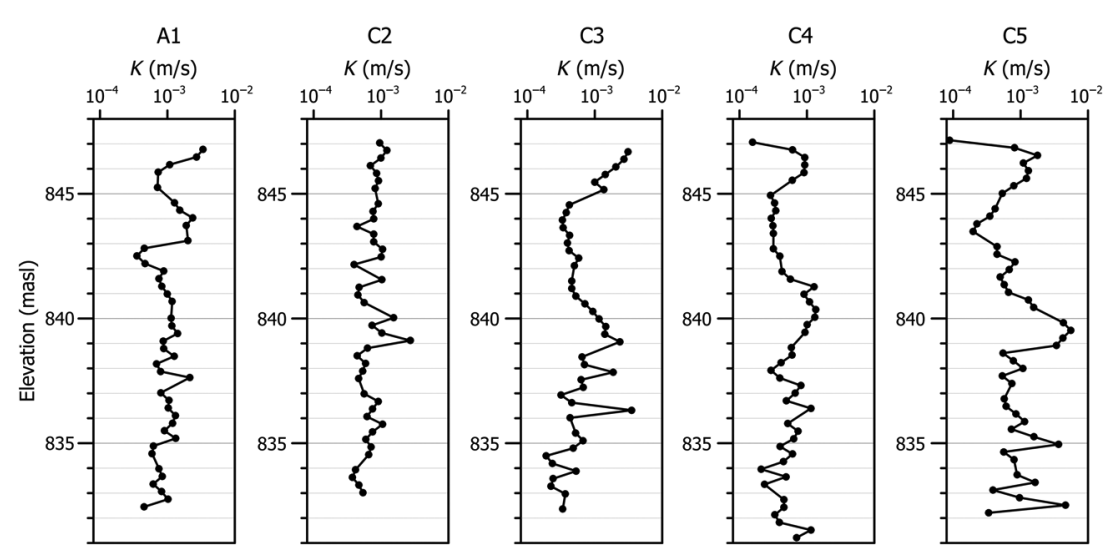

Figure 5. Example hydraulic conductivity profiles derived from multilevel slug tests (based on data in Barrash and Cardiff, 2013). 
determined. Reciprocal errors, in resistance magnitude and phase angle, were computed for each dipole configuration and were used to highlight anomalously high errors in magnitude and phase angle. We adopted error thresholds of $10 \%$ and $5 \mathrm{mrad}$ for the magnitude and phase angle, respectively (i.e., all data with errors above these thresholds were removed prior to inversion). The computed measurement errors are unsuitable for individual weighting of measurements because they only represent one sample of error for a given configuration. By grouping measurements (ranked by magnitude or phase angle) into "bins," we can examine trends in errors to allow the development of a simple representative error model. Köestel et al. (2008) use this approach for DC resistivity measurements. Flores Orozco et al. (2012) and Mwakanyamale et al. (2012) extend the method for complex conductivity measurements. We established clear relationships (see Figure 6) between the reciprocal error of magnitude $\varepsilon_{R}$ and phase angle $\varepsilon_{\varphi}$, and the resistance magnitude $R$ :

$$
\begin{aligned}
& \left|\varepsilon_{R}\right|(\text { in ohms })=0.0147|R|^{0.92} \\
& \left|\varepsilon_{\varphi}\right|(\text { in } \operatorname{mrad})=1.637-0291 \ln (|R|) .
\end{aligned}
$$

The (almost) linear relationship between $\log _{10}\left|\varepsilon_{R}\right|$ and $\log _{10}|R|$ is a commonly observed error structure (LaBrecque et al., 1996). In contrast, the reduction in phase angle error $\left|\varepsilon_{\varphi}\right|$ with an increasing $|R|$ highlights the impact of signal strength on the resolution of the IP effect. Measured phase angles were in the range of 0-15 mrad. As is normal practice (Slater and Binley, 2006), we assume a Gaus-

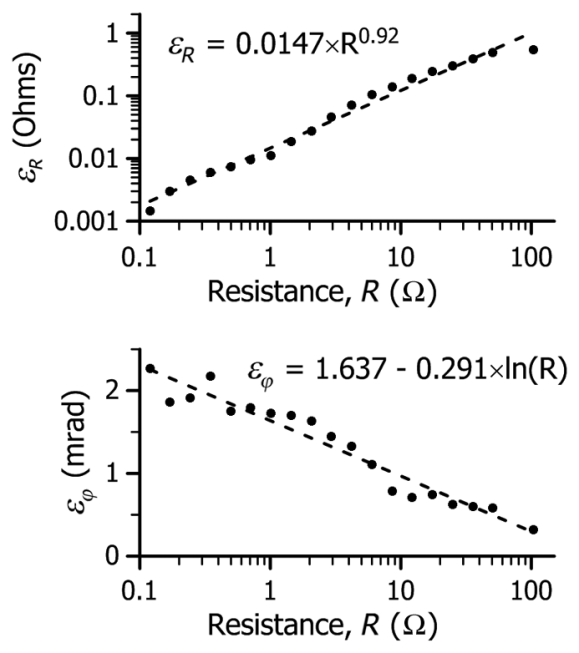

Figure 6. Error relationships for complex resistivity data.

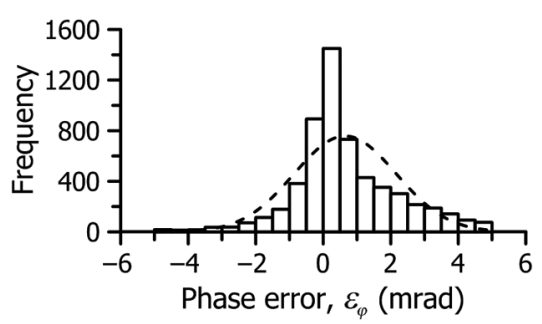

Figure 7. Distribution of phase angle reciprocity errors. Dashed line shows the Gaussian distribution for same sample mean and standard deviation as observed distribution. sian distribution of errors in our inversion process; Figure 7 shows some departure from this model and a slight positive bias.

\section{Inversion of complex conductivity measurements}

The apparent complex resistance magnitude and phase measurements were inverted to provide 3D distributions of complex conductivity, expressed in terms of magnitude and phase, using the program $c R 3 t$ (developed by A. Binley at Lancaster University). The $c R 3 t$ program solves the forward problem using a finite-element approximation adopting linear six-node triangular prism elements or four-node tetrahedral elements. A finite-element mesh containing 483,448 triangular prism elements and 246,078 nodes was created to model the potential field within the zone of study. The model region extends $130 \mathrm{~m}$ laterally (in both directions) and $80 \mathrm{~m}$ in depth to account for "infinite" boundary conditions using progressively coarser discretization with increasing distance from the well field. Discretization within the well field zone was approximately $0.4 \mathrm{~m}$ (lateral) and $0.2 \mathrm{~m}$ (vertical), i.e., three elements per electrode spacing in the vertical.

Although (four node) tetrahedral elements are computationally more efficient for solving the forward problem, we adopted triangular prism elements for this study because (1) the electrode positions in the vertical were identical for each well, thus making mesh generation relatively straightforward and (2) grouping elements to form parameter blocks is more easily achieved with such a mesh. The latter enhances computational efficiency significantly. For the inverse solution we discretized the region into 42,364 parameter blocks aligned to the forward modeling mesh boundary, with resolution reduced by a factor of exactly four in the vertical direction and by approximately three for the planar triangulation, as optimized by the mesh generator program.

The 3D complex conductivity inversion algorithm used is a $3 \mathrm{D}$ extension of the 2D algorithm described by Binley and Kemna (2005) and follows the Gauss-Newton method, incorporating an iterative refinement of the regularization parameter $\alpha$ that minimizes an objective function $\Psi$ composed of a data misfit term and a model stabilization term,

$$
\Psi=\left\|\boldsymbol{W}_{d}(\boldsymbol{d}-\boldsymbol{f}(\boldsymbol{m}))\right\|^{2}+\alpha\left\|\boldsymbol{W}_{m} \boldsymbol{m}\right\|^{2},
$$

where $\boldsymbol{W}_{d}$ is a data-weighting matrix associated with individual errors for each measurement, $\boldsymbol{d}$ and $\boldsymbol{f}$ are the vectors describing the measured data and forward solution for model vector $\boldsymbol{m}$, respectively, and $\boldsymbol{W}_{m}$ is a smoothness constraint representing the model weighting matrix, which is structured to allow anisotropic smoothing. For the inversions here, we adopted a 50:1 horizontal-to-vertical anisotropic smoothing to account for the observed horizontal correlation in stratigraphic unit boundaries (Figure 4); Attwa and Günther (2013) adopt a similar anisotropic smoothing in their inversion of 2D complex conductivity data. For our inversions, data $\boldsymbol{d}$ are expressed as an impedance magnitude and phase angle and model vector $\boldsymbol{m}$ is expressed as a complex conductivity magnitude (log value) and phase angle. The log transformation constrains the inversion to positive solutions.

Convergence of the iterative scheme is assumed when the mean of the data misfit component of equation 6 (averaged over the number of measurements) is unity. Given that the formulation expressed in terms of complex conductivity will bias the solution to satisfactory fitting of the magnitude values, as in Kemna (2000), we adopt a 
"final phase improvement" scheme, allowing refinement of the parameter phase angles in the final stages of the inversion while maintaining the magnitude values determined from the convergence of the first stage of the process.

\section{Cluster analysis}

To assess the value of complex resistivity in differentiating hydrogeologic units, despite variation of electrical parameters within each unit, we used the $k$-means cluster analysis method (MacQueen, 1967), a nonhierarchical partitioning technique that has been successfully used in environmental (Tronicke et al., 2004; Van Arkel and Kaleita, 2014) and geophysical (Di Giuseppe et al., 2014) studies. The $k$-means method requires user selection of the number of groups, or clusters, into which a data set should be classified. Each parameter may also be emphasized or suppressed in its contribution to the identification of structure within the data set by the chosen method of standardization and by application of a weighting factor (Gnanadesikan et al., 1995). For a full description of the $k$-means algorithm, see, for example, Hartigan and Wong (1979) and Gan et al. (2007).

\section{RESULTS}

\section{Smoothness constrained inverted models}

Figure 8 shows the results of the inversion of complex resistivity data. A contrast of only one order of magnitude in real conductivity is apparent; this variation is dominated by the difference between cobble-dominated units (units 1-4) and the sand unit (unit 5), the latter showing higher real conductivity that is consistent with the observed high $\varnothing$ of these sediments (Figure 3 ). The capacitive probe logs reported in Mwenifumbo et al. (2009) as conductivity show a similar weak contrast, in their case between 0.5 and $3 \mathrm{mS} / \mathrm{m}$ ( -3.3 to -2.5 range in $\log _{10} \sigma^{\prime}$, expressed in $\mathrm{S} / \mathrm{m}$ ). More subtle variation in real conductivity exists throughout the cobble-dominated units, although a distinct contrast is seen at approximately 838 and 844 masl (e.g., at C5 in Figure 8a). By comparing Figure 8a with Figures 3 and 4 , these appear to coincide with the bases of units 2B and 4, respectively.

Some lateral variation in real conductivity is seen within the study region, the most notable being the thinning out of the upper conductive zone in the image toward wells C2 and C3 (Figure 8a). Given that we associate this feature with the sand unit (unit 5), this thinning out is consistent with observed contacts at wells (as illustrated in Figure 4; see also Barrash and Clemo, 2002). Other lateral variation of note is the greater vertical contrast in conductivity (in the lower third of the real and imaginary conductivity images in Figure $8 \mathrm{~b}$ and $8 \mathrm{c}$ between wells $\mathrm{C} 4$ and C5). However, this cannot be explained by the contrast in $\varnothing$ because these contrasts are all similar at approximately 835 masl in wells C3 and C2 (Figure 2).

Generally weak variation in computed phase angle exists (Figure $8 \mathrm{c}$ ), although contrasts are clearly visible. Figure 9 shows the distribution of normalized misfit for the measurements, i.e., the difference between the measured and modeled phase angle relative to the assumed error (from equation 5). Such a distribution should ideally be Gaussian with a zero mean and unit variance. The modeled phase angles are typically approximately $2-4 \mathrm{mrad}$, which are consistent with those observed from complex conductivity measurements on reconstituted samples from the site (Slater et al., 2014). A low phase angle appears to be associated with the sand unit (unit 5). The relatively weak variation in phase angle will be not only due in part to the subtle contrast in sediment properties but also due to the weaker signal-to-noise ratio $(\mathrm{S} / \mathrm{N})$ of the measured phase angle in comparison with resistance magnitude, despite great care in data acquisition and rigorous treatment of phase angle data errors (Figures 6 and 7). However, it is the imaginary conductivity that uniquely resolves polarization and, despite the weak variation in phase angle, this property helps emphasize contrasts within the study region (Figure $8 \mathrm{~b}$ ). In particular, the lower third of the imaged region shows distinctly greater polarization than the upper section.
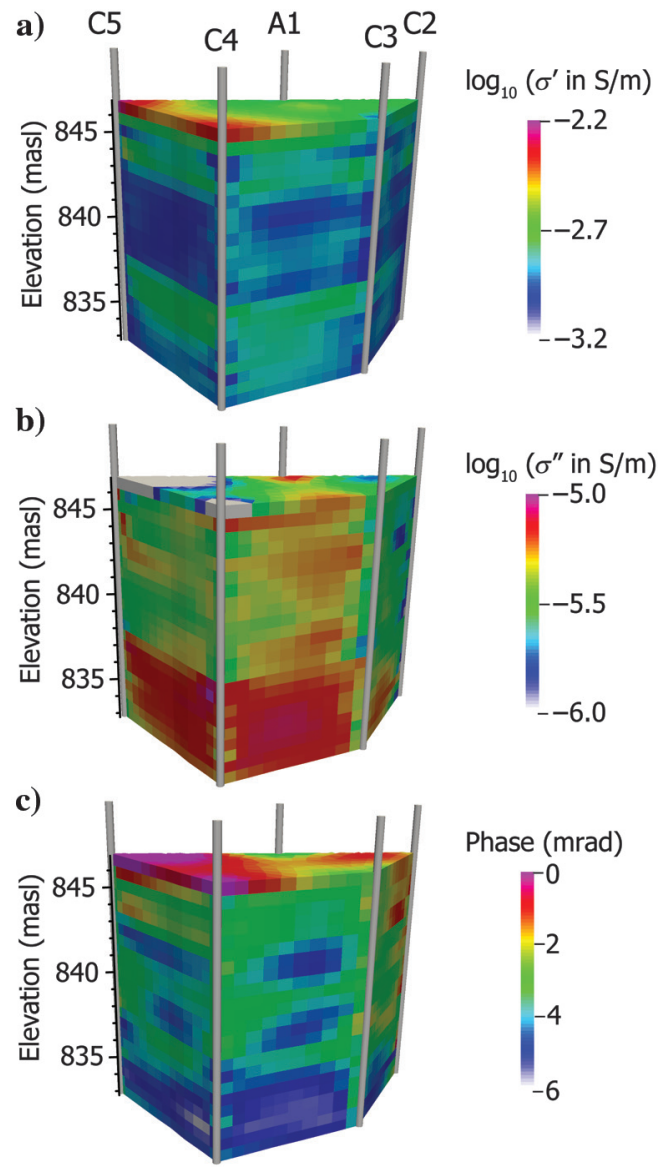

Figure 8. Complex resistivity inversion. (a) Real conductivity, (b) imaginary conductivity, and (c) phase angle.

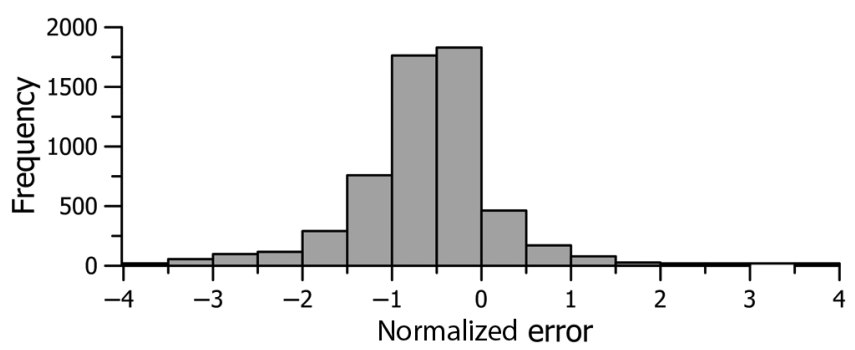

Figure 9. Distribution of normalized phase misfit for all measurements. 
Note also the very low polarization associated with the sand unit near boreholes $\mathrm{C} 4$ and $\mathrm{C} 5$.

Barrash and Clemo (2002) use the porosity logs (Figure 2) to develop probability density functions for unit-specific $\varnothing$ across the well field. Their analysis reveals contrasts in the distributions, for example, greater variance of $\varnothing$ in units 2 and 4, in comparison with units 1 and 3 (Figure 5 in Barrash and Clemo, 2002). Here, we could apply the same analysis using image voxel values at well locations. However, these would be limited to areas of higher imaging resolution and thus would be somewhat biased. Instead we use one of the unit boundary realizations (Figure 4) to delineate the complex resistivity image and thus allow the formation of unit-specific complex resistivity distributions. Figure 10 shows these distributions, expressed in terms of real conductivity and phase angle, for units 2A, 2B, 3, 4, and 5. Examining the real conductivity, we see a smaller variance in unit 3 compared with units 4 and 5, as in Barrash and Clemo (2002). We also note that units $2 \mathrm{~A}$ and $2 \mathrm{~B}$ combined (equivalent to unit 2 in Barrash and Clemo, 2002) also have larger variance than unit 3 . However, interestingly, given the newer unit 2 subdivision, units $2 \mathrm{~B}$ and 3 are relatively indistinguishable in terms

Unit 5
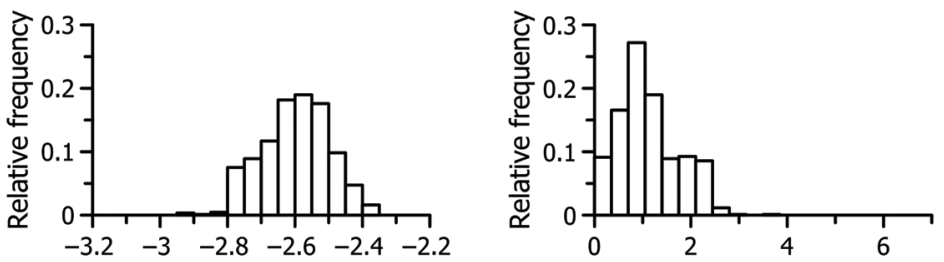

Unit 4

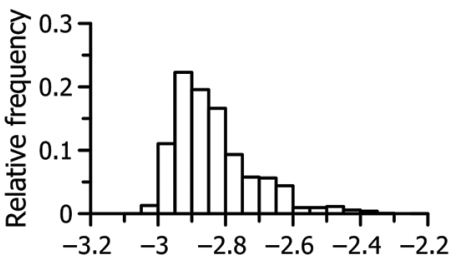

Unit 3

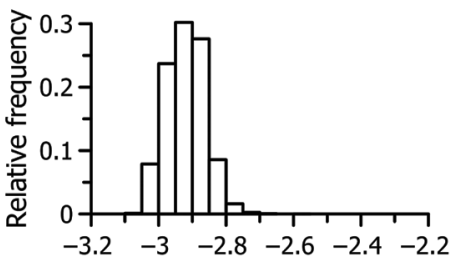

Unit 2B

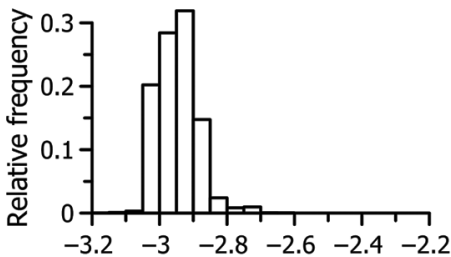

Unit 2A
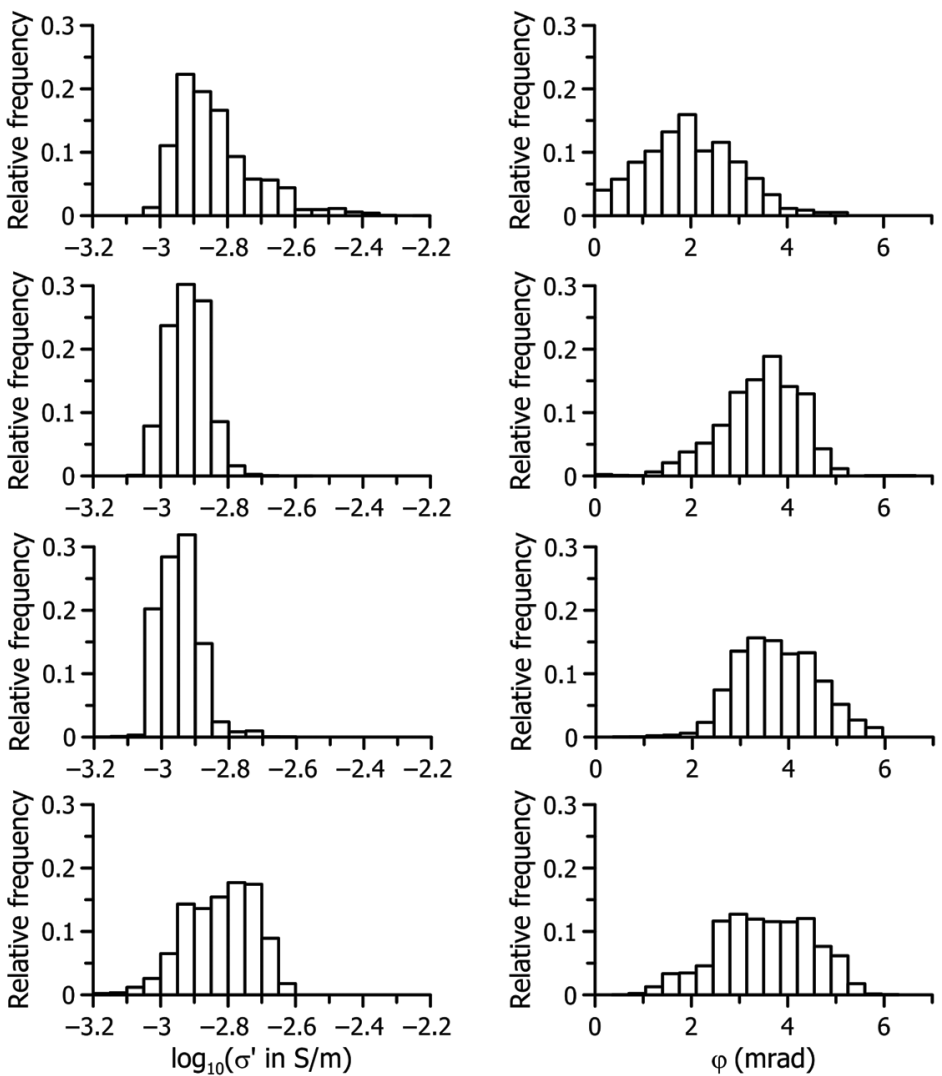

Figure 10. Variation in real conductivity magnitude (left column) and phase angle (right column) for image values in Figure 8, delineated into units following the stratigraphy in Figure 4. of real conductivity distributions although a subtly lower mean conductivity is apparent for unit $2 \mathrm{~B}$ when compared with unit 3 , which is consistent with the capacitive probe conductivity logs of Mwenifumbo et al. (2009) noted earlier. The phase angle distributions also show contrasts across some units (e.g., units 3 and 4), and again close similarity between unit $2 \mathrm{~B}$ and unit 3 .

bove comparison assumes that each computed electrical

\section{Cluster analysis}

The inversion results were projected from the irregular mesh used in the inversion to orthogonal grids $(80 \times 40 \times 60$ elements $)$ with a resolution selected as a compromise between computational complexity and excessive smoothing. Only the inverted results within the volume bounded by the electrode arrays were used. Five parameter values at each voxel were standardized by unit normalizing to a value between zero and one, representing the maximum and minimum values for each parameter. The parameters consisted of the $x, y$, and $z$ spatial coordinates together with two parameters representing complex conductivity expressed either as phase angle and the logarithm of magnitude, or as the logarithms of the imaginary and real components. Cluster analysis was carried out using either five or six clusters; these values were chosen because application of multiple analyses with identical values for all other parameters showed the greatest consistency with five clusters, slightly reduced consistency with six clusters, and poor consistency with four or seven clusters. Furthermore, analyses with five or six clusters allowed comparisons to be made with previous interpretations of BHRS stratigraphy based on $\varnothing$, lithology, and CR (Barrash and Clemo, 2002; Barrash and Reboulet, 2004; Mwenifumbo et al., 2009). Each identified cluster could include any nonzero proportion of the total number of voxels in the grid and could have irregular and discontinuous boundaries.

For selected cluster analyses, using five or six clusters, the nonparametric Kolmogorov-Smirnov test (Conover, 1999) was applied to determine whether the 3D distribution of $\sigma^{\prime}$ within each identified cluster differs significantly from the distribution within every other cluster, and this was repeated to test for significantly different distributions of $\sigma^{\prime \prime}$. In all cases, the null hypothesis that the distributions do not differ can be rejected $\left(p<10^{-4}\right)$.

Figure 11 shows 3D representations of our five-cluster analysis using DC conductivity only (Figure 11a), and using DC conductivity and IP data (Figure 11b). Only subtle differences are noticeable, highlighting that the lithologic boun- 
dary differentiation is most strongly influenced by the DC conductivity. Example cluster analysis results are shown in Figures 12 and 13 for extracted profiles at well locations $\mathrm{C} 4$ and B4, respectively. Well B4 (for location, see Figure 1) was selected as an example between the electrode array locations (where resolution of the electrical imaging is weaker). Figures 12 and 13 show the results for five- and six-unit cluster analysis, together with the previously defined unit boundaries. In both examples, clusters $\mathrm{K} 3$ and $\mathrm{K} 4$ for the five-cluster model closely represent clusters $\mathrm{K} 3$ to $\mathrm{K} 5$ in the sixcluster model, revealing that this interval is the zone of the weakest contrast. The six-cluster model, in both cases, shows close similarity to the unit boundaries (shown as units U1-U5 in Figures 12 and 13). Although the boundaries do not match perfectly, features such as the thinning of unit 4 from well $\mathrm{B} 4$ to $\mathrm{C} 4$ are clearly visible. The boundary between units $2 \mathrm{~B}$ and 3 , although subtle in terms of real conductivity, is well-resolved in both cases, supporting the earlier comments about differences in electrical conductivity between these two units. A distinct contrast in imaginary conductivity is seen at the unit $2 \mathrm{~A}-2 \mathrm{~B}$ boundary in both cases.

\section{DISCUSSION}

In this study, we have inverted cross-borehole time-domain measurements of complex electrical conductivity. Our results show some correspondence between the real and imaginary components of the 3D distributed values of complex conductivity in parts of the domain and also areas of contrasting behavior (Figure 8). We also note that the equipment required to record time-domain complex electrical measurements requires little additional time to deploy (relative to a frequency-domain spectral IP survey), over an equivalent DC survey.

a)

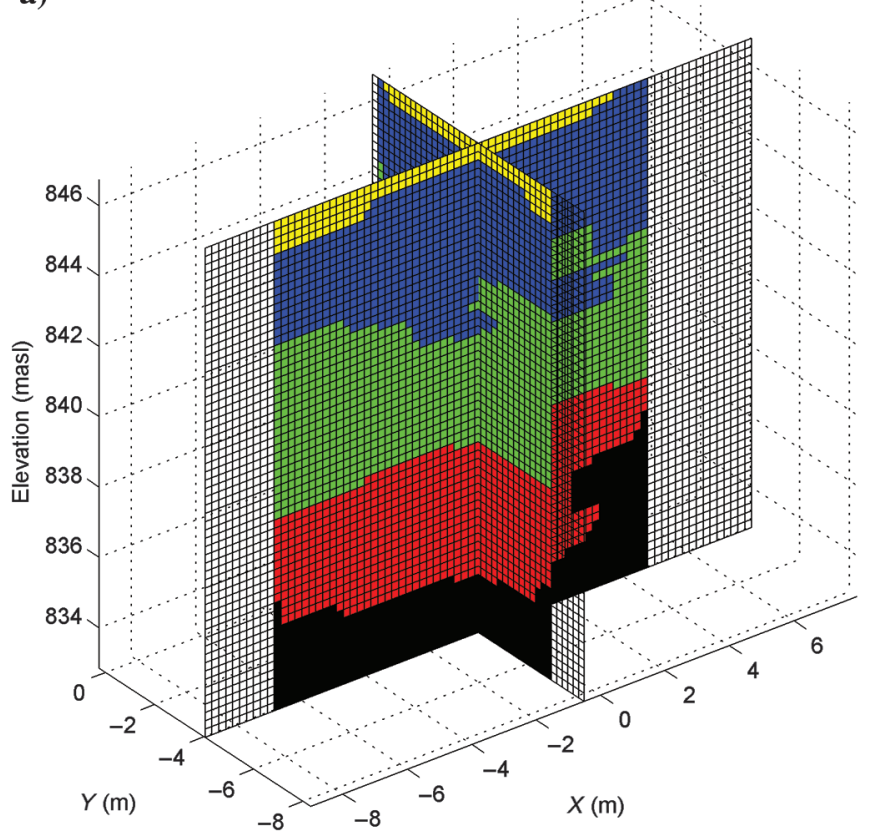

\section{$\mathrm{K}$ information}

The aquifer at the BHRS site has fairly low heterogeneity in $K$, with a range of $6.4 \times 10^{-5}$ to $1.6 \times 10^{-2} \mathrm{~ms}^{-1}$ (Barrash and Cardiff, 2013) and a lack of strong overall correlation between $K$ and $\varnothing$ (Cardiff et al., 2011). Indeed the $K$ distribution has positive and negative associations with $\varnothing$ in lower and upper portions of the stratigraphy, respectively (Barrash and Cardiff, 2013; Cardiff et al., 2013), indicating that only in portions of the coarse unconsolidated sediments at the BHRS is $K$ more strongly influenced by overall $\varnothing$

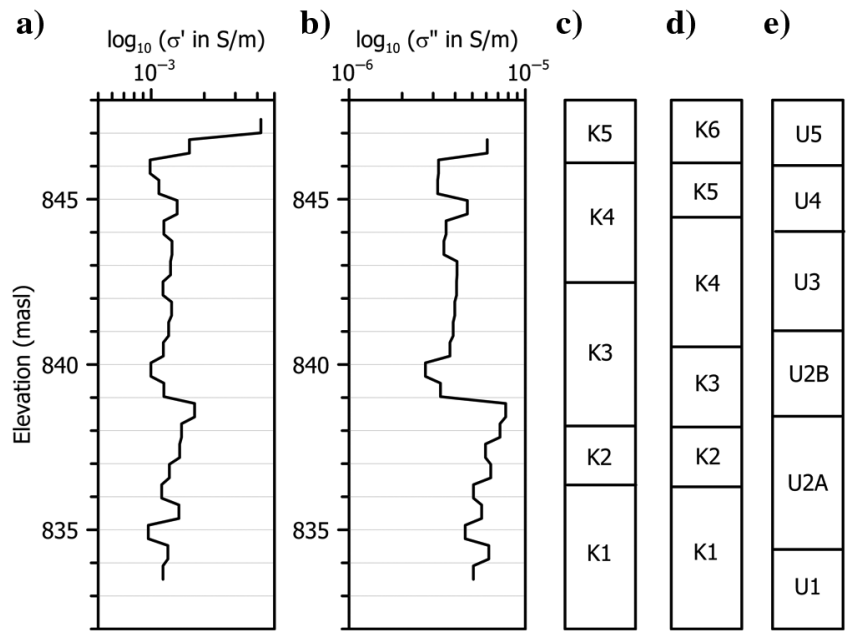

Figure 12. Cluster analysis results for well C4: (a) real conductivity profile from inversion, (b) imaginary conductivity profile from inversion, (c) cluster boundaries from five-cluster analysis, (d) cluster boundaries from six-cluster analysis, and (e) unit boundaries (Barrash and Clemo, 2002; Mwenifumbo et al, 2009).

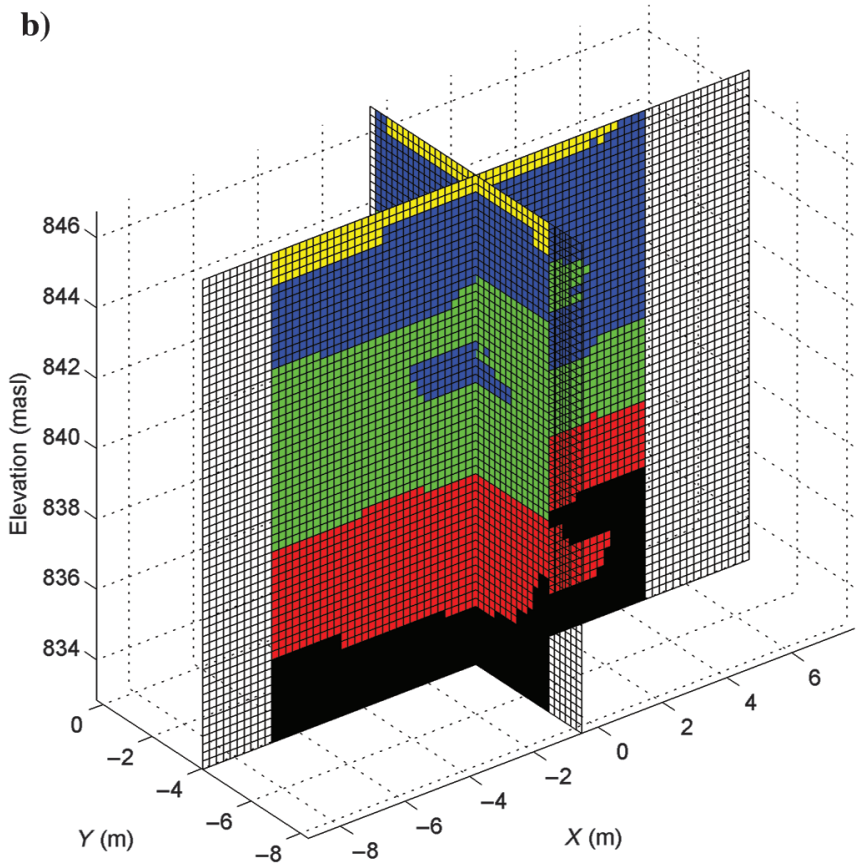

Figure 11. Results of five-cluster analysis showing (a) clusters based on real conductivity and (b) clusters based on real and imaginary conductivities. 
than by the surface area and tortuosity of the pore channels (which control $S_{\text {por }}$ ). We suggest that the additional information in the imaginary component of IP measurements is more likely to be correlated to $S_{\text {por }}$ in consolidated materials such as sandstones in which the surface area of pores and channels can vary almost independently of $\varnothing$. The lack of variability in field scale $\sigma^{\prime \prime}$ limits the estimation of subtle spatial variation of $S_{\text {por }}$, and hence $K$, using the relationships developed by, for example, Börner and Schön (1991), Börner et al. (1996), Slater and Lesmes (2002b), and Weller et al. (2010). However, to investigate IP-derived estimates of hydraulic conductivity, we draw on the recent relationship empirically derived by Weller et al. (2015) from a data set of 22 unconsolidated laboratory samples. They propose the link (equation 24 in Weller et al., 2015 ) between permeability $k$ (in $\mathrm{m}^{2}$ ) and complex electrical conductivity ( $\sigma$ and $\sigma^{\prime \prime}$ expressed in $\mathrm{mS} / \mathrm{m}$ ) as
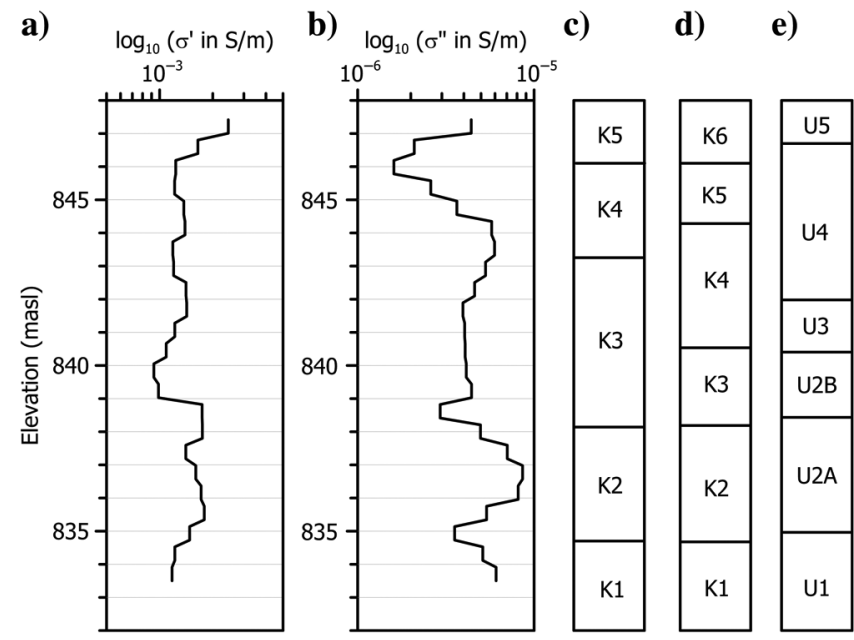

Figure 13. Cluster analysis results for well B4: (a) real conductivity profile from inversion, (b) imaginary conductivity profile from inversion, (c) cluster boundaries from five-cluster analysis, (d) cluster boundaries from six-cluster analysis, and (e) unit boundaries (Barrash and Clemo, 2002; Mwenifumbo et al, 2009).

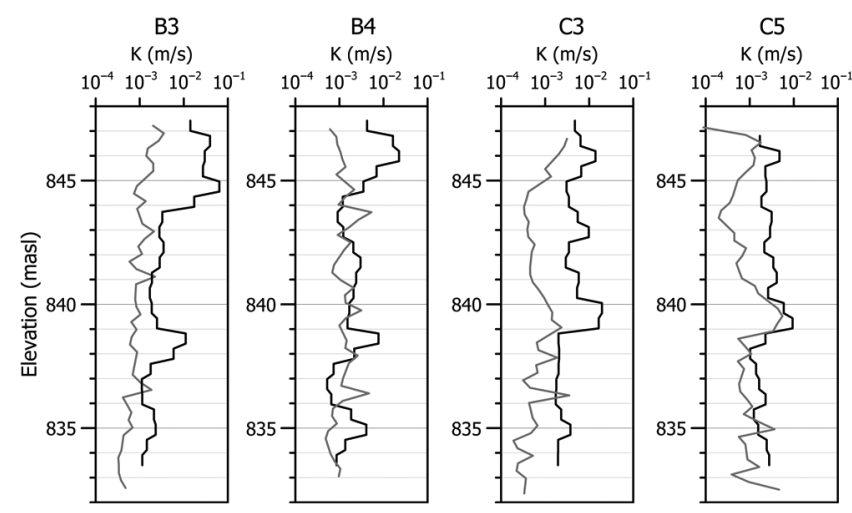

Figure 14. Example profiles of hydraulic conductivity. Black line values computed using equation 7 using complex conductivity values. Gray line - values from multilevel slug test data in Barrash and Cardiff (2013). Note the closer correspondence in the lower portion of the stratigraphy in which $K$ and porosity are more related in the Kozeny-Carman sense (Barrash and Cardiff, 2013).

$$
k=\frac{3.47 \times 10^{-16} \sigma^{1.11}}{\sigma^{\prime 2.41}},
$$

assuming a fluid conductivity $\sigma_{w}=100 \mathrm{mS} / \mathrm{m}$. Fluid electrical conductivity at the site is typically $20 \mathrm{mS} / \mathrm{m}$ (Hausrath et al., 2002); however, the two electrical parameters in equation 7 are easily scaled to reflect this (see e.g., Weller et al., 2015).

Figure 14 shows example profiles of hydraulic conductivity computed using equation 7 , using complex conductivity values from the inverse model (Figure 8). The profiles in Figure 14 show multilevel slug-test estimates of hydraulic conductivity for comparison. From the profiles in Figure 14, the difference between values from the hydrogeologic and geophysical measurements is typically within an order of magnitude. The correspondence is closer in the lower portion of the stratigraphy in which $K$ and porosity are related, although in the upper units of B3 and B4, the low polarization results in a much higher estimate of $K$, in which $K$ and porosity are poorly related (Barrash and Cardiff, 2013). The differentiation of subtle changes in hydraulic conductivity is, however, more challenging. Figure 14 shows similar locations of some smaller scale features (lenses) in each well but with variable polarity in slug data versus $K$ estimates from equation 7 because in situ measurements reflect nonuniform dependence of slug $K$ on porosity, grain size distribution, shape, and packing (detailed in Barrash and Cardiff, 2013).

Slater et al. (2014) find that relationships among $\sigma^{\prime \prime}$, effective grain size (best represented by the grain diameter for which $60 \%$ of the sample is finer), and $K$ could be identified from controlled laboratory-scale measurements on 12 samples spanning the five units originally identified at the BHRS (Barrash and Clemo, 2002; Barrash and Reboulet, 2004). In these reconstituted samples, $K$ only varied by about a factor of three, and thus, the full range of $K$ at the site was not captured. The ability to identify electrical-hydraulic relationships over such a narrow range of $K$ would on its own appear to encourage field-scale IP measurements for mapping hydrogeologic structures in such settings. Findings from this field study tend to support this conclusion; however, contrasts in field-based estimates from inversion may be difficult to determine in relatively low-contrast sedimentary aquifers, despite considerable efforts to minimize noise and careful estimation of the error structure within the measurements.

\section{Units and multiscale structure}

Our attempts to use the geophysical data for the identification of hydrogeologic units have revealed some additional information within $\sigma^{\prime \prime}$ beyond that within $\sigma^{\prime}$ at the BHRS. We note the ability of the $k$-means cluster analysis method to simplify the 3D distribution of $\sigma^{\prime}$, by identifying a predetermined number of regions approximated as horizontal layers. Application of the KolmogorovSmirnov test has shown that the empirical distribution of $\sigma^{\prime}$ values in each of the identified layers is significantly different from that of every other layer, confirming that the layered structures identified through cluster analysis relate to geophysical differences, despite the relatively high emphasis given to the vertical dimension in the inversion and clustering procedures. Vertical 1D samples through the simplified layered structure identified by the cluster analysis, such as at the positions of boreholes B4 and C4 (Figures 12 and 13), show good correlation between the layer boundaries and the boundaries between the stratigraphic units. The delineation of the unit $2 \mathrm{~A} /$ unit $2 \mathrm{~B}$ boundary is noticeably emphasized by the $\sigma^{\prime \prime}$ profile (see Figures 12 and 13). Results of the cluster analysis of the 3D inver- 
sion of $\sigma^{\prime}$ measurements are broadly supportive of the multiscale heterogeneity affecting hydraulic, lithologic, and geophysical parameters, which has been demonstrated in the sedimentary structure of the site (Barrash and Clemo, 2002; Barrash and Reboulet, 2004), and recognition of two types of electrical-porosity (and dielectric-porosity) behavior evident in the subdivision of unit 2 into units $2 \mathrm{~A}$ and $2 \mathrm{~B}$ (Ernst et al., 2007; Irving et al., 2007; Mwenifumbo et al. 2009; Dafflon et al., 2011b). Observation of $\varnothing$ and CR logs and analysis of correlation between $\varnothing$ and CR show strong correlation at the stratigraphic unit scale but highly variable weak to strong correlation at the subunit scale (Figure 14 here and Barrash and Cardiff, 2013).

The strong influence of the magnitude of complex conductivity on the imaginary conductivity appears to mask much of the apparent variation in IP when viewed in terms of phase angle. However, we note that, for example, units 3 and $2 \mathrm{~B}$ appear to show similar real conductivity but differ noticeably in phase angle (Figure 10). We have focused our analysis and interpretation here using $\sigma^{\prime}$ and $\sigma^{\prime \prime}$ as measures of conduction and polarization; however, future studies may seek to establish grounds for incorporating the phase angle as a means of discriminating hydrogeologic units.

\section{Frequency-related IP properties}

Our complex electrical measurements were recorded in the time domain, with a fixed step duration, converted to equivalent frequency-domain measurements recorded at a single frequency (in this case, $0.25 \mathrm{~Hz}$ ). The phase components of the complex electrical resistance values that were used in the inversion were derived from a simple relationship between phase and normalized chargeability. Although the validity of this relationship has been demonstrated in several studies (Kemna et al., 1997; Mwakanyamale et al., 2012), we speculate that a lower correlation between the magnitude and phase components might be observed if complex electrical measurements were directly recorded in the frequency domain as done in the laboratory. Other studies have investigated frequency-domain measurements of IP in porous materials recorded over a broad spectrum of frequencies, with attempts to link a frequency-related property of IP to physical properties of the material.

An overview of this SIP approach in near-surface investigations has been provided by Kemna et al. (2012), and identification of mechanistic relationships between physical properties which control hydraulic conductivity and SIP parameters continues to be an active and promising area of research (Florsch et al., 2012; Revil et al., 2015). However, as previously noted, this site is characterized by sediments that show very small differences in frequency-related properties between the units, suggesting that SIP studies will show the same limitations as IP methods at $\varnothing$-dominated sites with low heterogeneity in hydraulic characteristics of interest. We also note recent efforts to analyze time series of time-domain IP data in an attempt to remove superposition of charging cycles (Fiandaca et al., 2013). Such approaches, although currently limited to $2 \mathrm{D}$ analysis and specific polarization models, may offer greater ability to resolve more subtle contrasts in complex conductivity, especially in which there is evidence for additional (i.e., not K-C) petrophysics that is not dominated by $\varnothing$ (Morin, 2006; Barrash and Cardiff, 2013).

\section{CONCLUSIONS}

Our study has demonstrated that the field-scale IP approach may be suitable for providing estimates of hydraulic conductivity in coarse-grained aquifers but somewhat limited for the resolution of small-scale (e.g., lenses versus layers, Figure 14) contrasts in hydraulic conductivity variation. Despite the acquisition of highquality complex electrical measurements and careful handling in the inversion procedure of the estimated data errors, it is clear that low contrast in $K$ at the BHRS resulted in relatively low structural resolution based on the distribution of IP parameters.

Although our investigation was unsuccessful in providing a clear description of the distribution of $K$ in the central region of the BHRS, a site with (1) low-to-moderate $K$ heterogeneity typical of many high-energy coarse unconsolidated aquifers and (2) multiple relations between $K$ and $\varnothing$, we show that the purely conductive component of our complex measurements has provided supporting evidence for a stratigraphic structure including low-contrast features identified in previous investigations. We have shown the value of $k$-means cluster analysis in simplifying and identifying structure from complicated parameter distributions.

Our results have highlighted the potential danger of interpreting IP images from similar environments independently of other data. In many highly permeable aquifer systems, a level of heterogeneity of hydraulic properties that can influence flow and solute transport may be subtle from an electrical geophysics perspective. Obtaining high-quality IP measurements is not straightforward and the $\mathrm{S} / \mathrm{N}$ in polarization measurements may limit its use in noisy and/or poorly controlled settings. However, when significant contrasts in sediment properties are expected, we believe that IP has significant potential, e.g., in identification of hydrogeologic boundaries, perhaps at multiple scales.

Finally, we note that our analysis has used a commonly used smoothness-based inversion for our geophysical data. We adopted this as a means of evaluating the value of IP using widely acceptable procedures. However, one may envisage greater resolution of IP contrasts at sites, such as the BHRS, where other a priori information is used to constrain the inversion. We expect to see greater awareness and application of this approach in future studies.

\section{ACKNOWLEDGMENTS}

This material is based on work supported by the National Science Foundation under grant nos. EAR-0711053 and EAR-0710949. J. Heenan, B. Johnson, and M. Thoma provided valuable field assistance. A. Binley acknowledges the long-term exchanges with A. Kemna that allowed the development of the $3 \mathrm{D}$ inversion code cR3t. We are grateful to A. Weller, A. Hördt, and an anonymous reviewer for their constructive reviews of an earlier version of the manuscript.

\section{REFERENCES}

Archie, G. E., 1942, The electrical resistivity log as an aid in determining some reservoir characteristics: Transactions of the American Institute of Mining and Metallurgical Engineers, 146, 54-62.

Attwa, M., and R. Günther, 2013, Spectral induced polarization measurements for predicting the hydraulic conductivity in sandy aquifers: Hydrology and Earth System Sciences, 17, 4079-4094, doi: 10.5194/hess-17-4079-2013.

Barrash, W., and M. Cardiff, 2013, Hydraulic conductivity distribution from multi-level slug tests and multivariate facies associations in a conglomerate fluvial aquifer, Boise Hydrogeophysical Research Site: Tech. Rep. BSU CGISS 13-03, 71.

Barrash, W., and T. Clemo, 2002, Hierarchical geostatistics and multifacies systems, Boise Hydrogeophysical Research Site: Water Resources Research, 38, 14-1-14-18, doi: 10.1029/2002WR001436.

Barrash, W., T. Clemo, J. J. Fox, and T. C. Johnson, 2006, Field, laboratory, and modeling investigation of the skin effect at wells with slotted casing, 
Boise Hydrogeophysical Research Site: Journal of Hydrology, 326, 181198, doi: 10.1016/j.jhydrol.2005.10.029.

Barrash, W., T. Clemo, and M. D. Knoll, 1999, Boise Hydrogeophysical Research Site (BHRS): Objectives, design, initial geostatistical results: Proceedings of the Symposium on the Application of Geophysics to Engineering and Environmental Problems, 389-398.

Barrash, W., and E. C. Reboulet, 2004, Significance of porosity for stratigraphy and textural composition in subsurface coarse fluvial deposits, Boise Hydrogeophysical Research Site: Geological Society of America Bulletin, 116, 1059-1073, doi: 10.1130/B25370.1.

Bentley, L. R., and M. Gharibi, 2004, Two- and three-dimensional electrical resistivity imaging at a heterogeneous remediation site: Geophysics, 69 , 674-680, doi: 10.1190/1.1759453.

Binley, A., and A. Kemna, 2005, DC resistivity and induced polarization methods, in Y. Rubin, and S. S. Hubbard, eds., Hydrogeophysics: Water science and technology library: Springer, 523 .

Börner, F. D., 1992, Complex conductivity measurements of reservoir properties, in P. F. Worthington, and C. Chardaire-Riviere, eds., Proceedings of the Third European Core Analysis Symposium: Harwood Academic, 359-386.

Börner, F. D., and J. H. Schön, 1991, A relation between the quadrature component of electrical conductivity and the specific surface area of sedimentary rocks: The Log Analyst, 32, 612-613.

Börner, F. D., J. R. Schopper, and A. Weller, 1996, Evaluation of transport and storage properties in the soil and groundwater zone from induced polarization measurements: Geophysical Prospecting, 44, 583-601, doi: 10.1111/gpr.1996.44.issue-4.

Brauchler, R., R. Hua, T. Vogta, D. Al-Halbounib, T. Heinrichsa, T. Ptaka, and M. Sautera, 2010, Cross-well slug interference tests: An effective characterization method for resolving aquifer heterogeneity: Journal of Hydrology, 384, 33-45, doi: 10.1016/j.jhydrol.2010.01.004.

Butler, J. J., 1998, The design, performance, and analysis of slug tests: CRC Press, 262

Cardiff, M., W. Barrash, and P. K. Kitanidis, 2012, A field proof-of-concept of aquifer imaging using 3-D transient hydraulic tomography with modular, temporarily-emplaced equipment: Water Resources Research, 48, W05531, doi: 10.1029/2011WR011704.

Cardiff, M., W. Barrash, and P. K. Kitanidis, 2013, Hydraulic conductivity imaging from 3-D transient hydraulic tomography at several pumping/observation densities: Water Resources Research, 49, 1-6, doi: 10.1029/2012WR012444.

Cardiff, M. W. Barrash, P. K. Kitanidis, B. Malama, A. Revil, S. Straface, and E. Rizzo, 2009, A potential-based inversion of unconfined steadystate hydraulic tomography: Ground Water, 47, 259-270, doi: 10.1111/ j.1745-6584.2008.00541.x.

Cardiff, M., W. Barrash, M. Thoma, and B. Malama, 2011, Information content of slug tests for estimating hydraulic properties in realistic, high-conductivity aquifer scenarios: Journal of Hydrology, 403, 66-82, doi: 10 .1016/j.jhydrol.2011.03.044.

Cassiani, G., V Bruno, A. Villa, N. Fusi, and A. M. Binley, 2006, A saline trace test monitored via time-lapse surface electrical resistivity tomography: Journal of Applied Geophysics, 59, 244-259, doi: 10.1016/j.jappgeo .2005.10.007.

Charbeneau, R. J., 1999, Groundwater hydraulics and pollutant transport: Prentice Hall, 593.

Clement, W. P., M. D. Knoll, L. M. Liberty, P. R. Donaldson, P. Michaels, W. Barrash, and J. R. Pelton, 1999, Geophysical surveys across the Boise Hydrogeophysical Research Site to determine geophysical parameters of a shallow, alluvial aquifer: Proceedings of the Symposium on the Application of Geophysics to Engineering and Environmental Problems, 399-408.

Conover, W. J., 1999, Practical nonparametric statistics: John Wiley, 592.

Dafflon, B., W. Barrash, M. Cardiff, and T. C. Johnson, 2011a, Hydrological parameter estimations from a conservative tracer test with variable-density effects at the Boise Hydrogeophysical Research Site: Water Resources Research, 47, W12513, doi: 10.1029/2011WR010789.

Dafflon, B., J. Irving, and W. Barrash, 2011b, Inversion of multiple intersecting high-resolution crosshole GPR profiles for hydrological characterization at the Boise Hydrogeophysical Research Site: Journal of Applied Geophysics, 73, 305-314, doi: 10.1016/j.jappgeo.2011.02.001.

Di Giuseppe, M. G., A. Troiano, C. Troise, and G. De Natale, 2014, k-Means clustering as tool for multivariate geophysical data analysis: An application to shallow fault zone imaging: Journal of Applied Geophysics, 101, 108-115, doi: 10.1016/j.jappgeo.2013.12.004.

Diem, S., T. Vogt, and E. Hoehn, 2010, Räumliche Charakterisierung der hydraulischen Leitfähigkeit in alluvialen Schotter-Grundwasserleitern: Ein Methodenvergleich: Grundwasser, 15, 241-251, doi: 10.1007/ s00767-010-0153-6.

Doetsch, J., N. Linde, M. Pessognelli, A. G. Green, and T. Günther, 2012, Constraining 3-D electrical resistance tomography with GPR reflection data for improved aquifer characterization: Journal of Applied Geophysics, 78, 68-76, doi: 10.1016/j.jappgeo.2011.04.008.

Ernst, J. R., A. G. Green, H. Maurer, and K. Holliger, 2007, Application of a new 2D time-domain full-waveform inversion scheme to crosshole radar data: Geophysics, 72, no. 5, J53-J64, doi: 10.1190/1.2761848.
Fiandaca, G., E. Auken, A. Vest Christiansen, and A. Gazoty, 2012, Timedomain-induced polarization: Full-decay forward modeling and laterally constrained inversion of Cole-Cole parameters: Geophysics, 77, no. 3, E213-E225, doi: 10.1190/geo2011-0217.1.

Fiandaca, G., J. Ramm, A. Binley, A. Gazoty, A. Vest Christiansen, and E. Auken, 2013, Resolving spectral information from time domain induced polarization data through 2-D inversion: Geophysical Journal International, 192, 631-646, doi: 10.1093/gii/ggs060.

Flores Orozco, A., A. Kemna, and E. Zimmermann, 2012, Data error quantification in spectral induced polarization imaging: Geophysics, 77, no. 3 , E227-E237, doi: 10.1190/geo2010-0194.1.

Florsch, N., C. Camerlynck, and A. Revil, 2012, Direct estimation of the distribution of relaxation times from induced-polarization spectra using a Fourier transform analysis: Near Surface Geophysics, 10, 517-531

Gan, G., C. Ma, and J. Wu, 2007, Data clustering, theory, algorithms, and applications: Statistics and applied probability: SIAM, 488.

Gnanadesikan, R., J. R. Kettenring, and S. L. Tsao, 1995, Weighting and selection of variables for cluster analysis: Journal of Classification, 12, 113-136, doi: 10.1007/BF01202271.

Griffiths, D. H., and J. Turnbull, 1985, A multi-electrode array for resistivity surveying: First Break, 3, 16-20, doi: 10.3997/1365-2397.1985013.

Hartigan, J. A., and W. A. Wong, 1979, Algorithm AS 136: A K-means clustering algorithm: Journal of the Royal Statistical Society. Series C (Applied Statistics), 28, 100-108.

Hausrath, E., W. Barrash, and E. Reboulet, 2002, Water sampling and analysis for the tracer/time-lapse radar imaging test at the Boise Hydrogeophysical Research Site: Technical Report BSU CGISS 02-03, Center for Geophysical Investigation of the Shallow Subsurface, Boise State University, 86 .

Hördt, A., R. Blaschek, F. Binot, A. Druiventak, A. Kemna, P. Kreye, and N. Zisser, 2009, Case histories of hydraulic conductivity estimation with induced polarisation at the field scale: Near-Surface Geophysics, 7, 529545 .

Hördt, A., R. Blaschek, A. Kemna, and N. Zisser, 2007, Hydraulic conductivity estimation from induced polarisation data at the field scale - The Krauthausen case history: Journal of Applied Geophysics, 62, 33-46, doi: 10.1016/j.jappgeo.2006.08.001.

Irving, J. D., M. D. Knoll, and R. J. Knight, 2007, Improving crosshole radar velocity tomograms: A new approach to incorporating high-angle traveltime data: Geophysics, 72, no. 4, J31-J41, doi: 10.1190/1.2742813.

Jardani, A., A. Revil, and J. P. Dupont, 2013, Stochastic joint inversion of hydrogeophysical data for salt tracer test monitoring and hydraulic conductivity imaging: Advances in Water Resources, 52, 62-77, doi: 10.1016/j.advwatres.2012.08.005.

Johnson, T. C., P. S. Routh, W. Barrash, and M. D. Knoll, 2007, A field comparison of Fresnel zone and ray-based GPR attenuation-difference tomography for time-lapse imaging of electrically anomalous tracer or contaminant plumes: Geophysics, 72, no. 2, G21-G29, doi: 10.1190/1 .2431638 .

Kemna, A., 2000, Tomographic inversion of complex resistivity: Theory and application: Ph.D. thesis, Der Andere Verlag, 176.

Kemna, A., A. Binley, G. Cassiani, E. Niederleithinger, A. Revil, L. Slater, K. H. Williams, A. F. Orozco, F.-H. Haegel, A. Hördt, S. Kruschwitz, V. Leroux, K. Titov, and E. Zimmermann, 2012, An overview of the spectral induced polarization method for near-surface applications: Near Surface Geophysics, 10, 453-468.

Kemna, A., A. Binley, and L. D. Slater, 2004, Crosshole IP imaging for engineering and environmental applications: Geophysics, 69, 97-107, doi: 10.1190/1.1649379.

Kemna, A., E. Räkers, and A. Binley, 1997, Application of complex resistivity tomography to field data from a kerosene-contaminated site: 3rd Meeting of the Environmental and Engineering Geophysics Society, $151-154$.

Köestel, J., A. Kemna, M. Javaux, A. Binley, and H. Vereecken, 2008, Quantitative imaging of solute transport in an unsaturated and undisturbed soil monolith with 3-D ERT and TDR: Water Resources Research, 44, W12411, doi: 10.1029/2007WR006755.

LaBrecque, D. J., M. Miletto, W. Daily, A. Ramirez, and E. Owen, 1996, The effects of noise on Occam's inversion of resistivity tomography data: Geophysics, 61, 538-548, doi: 10.1190/1.1443980.

Loke, M. H., J. E. Chambers, D. F. Rucker, O. Kuras, and P. B. Wilkinson, 2013, Recent developments in the direct-current geoelectrical imaging method: Journal of Applied Geophysics, 95, 135-156, doi: 10.1016/j. jappgeo.2013.02.017

MacQueen, J., 1967, Some methods for classification and analysis of multivariate observations, 5th Berkeley symposium on mathematical statistics and probability: University of California Press, 281-297.

Malama, B., K. L. Kuhlman, W. Barrash, M. Cardiff, and M. Thoma, 2011, Modeling slug tests in unconfined aquifers taking into account water table kinematics, wellbore skin and inertial effects: Journal of Hydrology, 408, 113-126, doi: 10.1016/j.jhydrol.2011.07.028. 
Morin, R. E., 2006, Negative correlation between porosity and hydraulic conductivity in sand-and-gravel aquifers at Cape Cod: Journal of Hydrology, 316, 43-52, doi: 10.1016/j.jhydrol.2005.04.013.

Mwakanyamale, K., L. D. Slater, A. Binley, and D. Ntarlagiannis, 2012, Lithologic imaging using complex conductivity: Lessons learned from the Hanford 300 Area: Geophysics, 77, no. 6, E397-E409, doi: 10 .1190/geo2011-0407.1.

Mwenifumbo, C. J., W. Barrash, and M. D. Knoll, 2009, Capacitive conductivity logging and electrical stratigraphy in a high-resistivity aquifer: Boise Hydrogeophysical Research Site: Geophysics, 74, no. 3, E125E133, doi: 10.1190/1.3106760.

Nelson, G., 2007, Deterministic modeling of bromide tracer transport during the tracer/time-lapse radar imaging test at the Boise hydrogeophysical research site in August, 2001: M.S. thesis, Boise State University.

Nimmer, R. E., J. L. Osiensky, A. M. Binley, and B. C. Williams, 2008, Three-dimensional effects causing artifacts in two-dimensional, crossborehole, electrical imaging: Journal of Hydrology, 359, 59-70, doi: 10.1016/j.jhydrol.2008.06.022.

Reboulet, E.C., and W. Barrash, 2003, Core, grain-size, and porosity data from the Boise Hydrogeophysical Research Site: BSU CGISS Technical Report, 03-02, Boise State University, 84.

Revil, A., A. Binley, L. Mejus, and P. Kessouri, 2015, Predicting permeability from the characteristic relaxation time and intrinsic formation factor of complex conductivity spectra: Water Resources Research, 51, 66726700, doi: 10.1002/2015WR017074.

Revil, A., and N. Florsch, 2010, Determination of permeability from spectral induced polarization in granular media: Geophysical Journal International, 181, 1480-1498.

Revil, A., and M. Skold, 2011, Salinity dependence of spectral induced polarization in sands and sandstones: Geophysical Journal International, 187, 813-824, doi: 10.1111/gji.2011.187.issue-2.

Slater, L. D., W. Barrash, J. Montrey, and A. Binley, 2014, Electricalhydraulic relationships observed for unconsolidated sediments in the presence of a cobble framework: Water Resources Research, 50, 5721-5742, doi: $10.1002 /$ wrer.v50.7.

Slater, L. D., and A. Binley, 2006, Synthetic and field-based electrical imaging of a zerovalent iron barrier: Implications for monitoring long-term barrier performance: Geophysics, 71, no. 5, B129-B137, doi: 10.1190/1.2235931.

Slater, L. D., A. M. Binley, W. Daily, and R. Johnson, 2000, Cross-hole electrical imaging of a controlled saline tracer injection: Journal of Applied Geophysics, 44, 85-102, doi: 10.1016/S0926-9851(00)00002-1.

Slater, L. D., and D. R. Glaser, 2003, Controls on induced polarization in sandy unconsolidated sediments and application to aquifer characterization: Geophysics, 68, 1547-1558, doi: 10.1190/1.1620628.

Slater, L. D., and D. Lesmes, 2002a, IP interpretation in environmental investigations: Geophysics, 67, 77-88, doi: 10.1190/1.1451353.
Slater, L. D., and D. P. Lesmes, 2002b, Electrical-hydraulic relationships observed for unconsolidated sediments: Water Resources Research, 38, 31-1-31-13, doi: 10.1029/2001WR001075.

Stummer, P., H. Maurer, H. Horstmeyer, and A. G. Green, 2002, Optimization of DC resistivity data acquisition: Real-time experimental design and a new multielectrode system: IEEE Transactions on Geoscience and Remote Sensing, 40, 2727-2735, doi: 10.1109/TGRS.2002.807015.

Sudicky, E. A., 1986, A natural gradient experiment on solute transport in a sand aquifer: Spatial variability of hydraulic conductivity and its role in the dispersion process: Water Resources Research, 22, 2069-2082, doi: 10.1029/WR022i013p02069.

Tronicke, J., K. Holliger, W. Barrash, and M. D. Knoll, 2004, Multivariate analysis of cross-hole georadar velocity and attenuation tomograms for aquifer zonation: Water Resources Research, 40, W01519, doi: 10 .1029/2003WR002031.

Van Arkel, Z., and A. L. Kaleita, 2014, Identifying sampling locations for field-scale soil moisture estimation using K-means clustering: Water Resources Research, 50, 7050-7057, doi: 10.1002/wrcr.v50.8.

Vaudelet, P., A. Revil, M. Schmutz, M. Franceschi, and P. Bégassat, 2011, Induced polarization signatures of cations exhibiting differential sorption behaviors in saturated sands: Water Resources Research, 47, W02526, doi: 10.1029/2010WR009310.

Vinegar, H. J., and M. H. Waxman, 1984, Induced polarization of shaly sands: Geophysics, 49, 1267-1287, doi: 10.1190/1.1441755.

Weller, A., and L. Slater, 2012, Salinity dependence of complex conductivity of unconsolidated and consolidated materials: Comparisons with electrical double layer models: Geophysics, 77, no. 5, D185-D198, doi: 10 $.1190 /$ geo2012-0030.1.

Weller, A., L. Slater, A. Binley, S. Nordsiek, and S. Xu, 2015, Permeability prediction based on induced polarization: Insights from measurements on sandstone and unconsolidated samples spanning a wide permeability range: Geophysics, 80, no. 2, D161-D173, doi: 10.1190/geo2014-0368.1.

Weller, A., L. Slater, and S. Nordsiek, 2013, On the relationship between induced polarization and surface conductivity: Implications for petrophysical interpretation of electrical measurements: Geophysics, 78, no. 5, D315D325, doi: 10.1190/geo2013-0076.1.

Weller, A., L. Slater, S. Nordsiek, and D. Ntarlagiannis, 2010, On the estimation of specific surface per unit pore volume from induced polarization: A robust empirical relation fits multiple data sets: Geophysics, $\mathbf{7 5}$ no. 4, WA105-WA112, doi: 10.1190/1.3471577.

Wolf, S. H., M. A. Celia, and K. M. Hess, 1991, Evaluation of hydraulic conductivities calculated from multiport-permeameter measurements Ground Water, 29, 516-525, doi: 10.1111/gwat.1991.29.issue-4.

Woodbury, A. D., and E. Sudicky, 1991, The geostatistical characteristics of the Borden aquifer: Water Resources Research, 27, 533-546, doi: 10.1029/90WR02545. 